\title{
Wh-question intonation in Peninsular Spanish: Multiple contours and the effect of task type
}

\author{
NICHOLAS C. HENRIKSEN
}

\begin{abstract}
This paper reports on an experimental investigation of wh-question intonation in Peninsular Spanish. Speech data were collected from six León, Spain Peninsular Spanish speakers, and oral production data were elicited under two conditions: a computerized sentence reading task and an information gap task-oriented dialogue. The latter task was an adaptation of the HCRC Map Task method (cf. Anderson et al., 1991) and was designed to elicit multiple wh-question productions in an unscripted and more spontaneous speech style than the standard sentence reading task. Results indicate that four contours exist in the tonal inventory of the six speakers. The two most frequent contours were a final rise contour and a nuclear circumflex contour. Systematic taskbased differences were found for four of the six speakers, indicating that sentence reading task data alone may not accurately reflect spontaneous speech tonal patterns (cf. Cruttenden, 2007; but see also Lickley, Schepman, $\&$ Ladd, 2005). The experimental findings serve to clarify a number of assumptions about the syntax-prosody interface underlying wh-question utterance signaling; they also have implications for research methods in intonation and task-based variation in laboratory phonology.
\end{abstract}

\section{Introduction}

Spanish is an intonational language, meaning that it uses relative differences in pitch to communicate different pragmatic or discourse meanings. It is not uncommon to find that intonational languages like Spanish employ variations in pitch to communicate different sentence types. In fact, one of the hallmarks of Spanish declarative and yes/no question signaling is that multiple intonational cues serve to disambiguate the meaning difference between these two sentences type (cf. Face, 2004, 2007). Within the Hispanic tradition, experimental research has sought to investigate the tonal patterns used to communicate the declarative vs. yes/no question contrast in terms of 
production (Face, 2004; Prieto, 2004; Willis, 2005, 2006/7; Alvord, 2007; Simonet, 2008) as well as perception (Face, 2005, 2007). Research focusing on Spanish wh-question intonation has been limited in comparison, and this may be due to the assumption that the obligatory use of the wh-word suffices to communicate this sentence type (cf. Quilis, 1993; Hualde, 2005). Although descriptive accounts of Spanish wh-question intonation have been put forth (Navarro Tomás, 1944; Quilis, 1987, 1993; Sosa, 1999), relatively few laboratory studies (i.e., with controlled speech materials) have been carried out (cf. Dorta, 2000; Sosa, 2003; Willis, 2006/7). Prieto (2004) is the only experimental study that examines wh-question intonation in the variety of Spanish spoken in mainland Spain. Prieto's study was not designed to examine the structure of wh-questions specifically, and speech data were limited to two speakers. The present investigation was designed to fill this gap in the experimental research on the intonation of Spanish wh-questions. In particular, it sought to identify the range of tonal contours available in the Peninsular Spanish wh-question inventory by analyzing data produced by six native speakers from León, Spain. ${ }^{1}$

A unique component of the current research design is that in addition to participating in a sentence reading task, native speaker informants partook in a short task-based dialogue, termed here a 'person identification task.' This task was designed as an adapted version of the Map Task (cf. Anderson et al., 1991), which has recently gained acceptance in experimental intonation research (e.g., Grice \& Savino, 2003; Lickley et al., 2005). Within the Hispanic tradition, the use of the sentence reading task has prevailed as the most recurrent methodology in work on intonation. Although other methods have been employed (see, for example, Simonet (2008) or Sosa (2003)), no study has yet to systematically compare speakers' productions of the same sentence type across two different task types. Face (2003) highlighted a number of differences between read and spontaneous speech, but the pragmatic implications of the spontaneous data could not be verified. Similarly, Willis (2004) and O'Rourke (2005) used spontaneous conversations to corroborate laboratory productions, but detailed task-based comparisons were not provided in either study. Thus, a second goal of this paper is to provide a principled comparison of wh-question tonal patterns produced in a sentence reading task and in a task-oriented dialogue by the same pool of native speaker participants. This research objective was implemented for a number of reasons. First, a review of current work on Spanish wh-question intonation indicates that multiple contour patterns may be available for use. Thus, the use of multiple tasks may serve to elicit a

\footnotetext{
${ }^{1}$ The city of León, Spain is located in northwest Spain, with a population of roughly 140,000 inhabitants. The variety of Spanish spoken in León is generally considered Castilian or Peninsular Spanish, spoken in the central and northern regions of mainland Spain. For information on León, Spain declarative and yes/no question intonation, the reader is directed to Willis \& Henriksen (2008).
} 
broader range of tonal patterns. Second, current research offers contradictory reports on the reliability of read aloud data as a reflection of naturalistic speech patterns (Face, 2003; Sosa, 2003; Lickley et al., 2005; Cruttenden, 2007).

\section{Previous literature}

\subsection{Wh-question intonation in Spanish}

Ladd (1996), in his work on intonational phonology and autosegmentalmetrical theory, observes two cross-linguistic tendencies in the intonational marking of wh-questions. ${ }^{2}$ In languages which exhibit wh-movement, the whword does not bear the prominent accent, suggesting that the wh-word is not the focus of the utterance. An example of this language type is English, where the last stressed syllable of the phrase-final word often bears the prominent accent. Languages such as Turkish and Bengali which lack wh-movement (i.e., in which the wh-word does not stand at the beginning of the utterance), in contrast, mark the pronominal word with an F0 rise (p. 170-172). Research on Spanish suggests that the neutral wh-question configuration contains an F0 rise on the pronominal word, despite the use of wh-movement for syntactic marking. Navarro Tomás (1950) distinguishes three configurations for whquestion intonation: an unmarked (i.e., default) falling contour; a pragmatically-motivated 'polite' contour characterized by a final rise; and a circumflex contour characterized by a final rise-fall which communicates amazement or surprise. Each is schematized in Figures 1a, 1b, and 1c respectively. Quilis (1993) also characterizes a 'falling' contour as the unmarked configuration for wh-question intonation, although according to Quilis' characterization, the fall is gradual and is not comprised of a drop on the final syllable, as Navarro Tomás had originally depicted. ${ }^{3}$ Quilis' 'falling' contour is identified by a rise on the question word followed by a gradual descent throughout the remainder of the utterance (see 1d). ${ }^{4}$ Hualde (2005) documents a similar pattern as the default configuration. Both Quilis (p. 431) and Hualde (2005, p. 267) underscore the prevalence of the question word and not tonal gestures per se - as the necessary cue for communicating a whquestion in Spanish. The tonal patterns which comprise the wh-question

\footnotetext{
${ }^{2}$ For other standard references on autosegmental and/or intonational phonology, the reader is directed to works such as Goldsmith (1979), Pierrehumbert (1980), or Beckman \& Pierrehumbert (1986).

${ }^{3}$ Specifically, Quilis (1993) employs the term "juntura terminal descendente [falling terminal juncture, translation mine]" (p. 431) to refer to the falling wh-question pattern.

4 The wh-question contour depicted in Navarro Tomás (1944, p. 210) is similar to what was proposed in Quilis (1993). It is not clear why a different falling contour was provided in Navarro Tomás (1950).
} 
contour are assumed to bear resemblance to those of the neutral declarative, and this property falls from a principle of economy: "Since economy in language tends to avoid redundancies, only one [linguistic] sign is sufficient to indicate the [wh-]question [translation mine]" (Quilis, p. 431). ${ }^{5}$ Thus, Quilis and Hualde contend that the overall configuration of the wh-question contour should correspond to the default declarative pattern. Experimental work on Peninsular Spanish intonation has yet to confirm this claim.

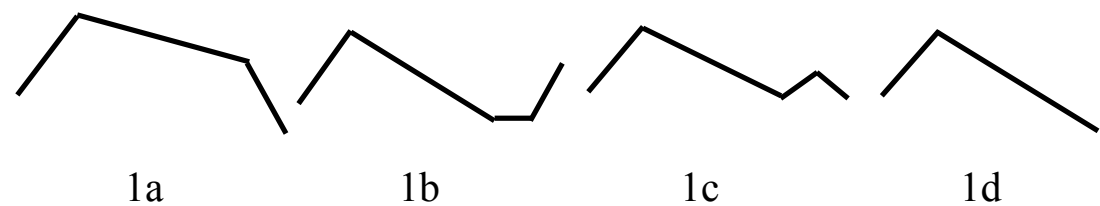

Figure 1. Wh-question configurations according to Navarro Tomás (1950) (1a-1c) and Quilis (1993) (1d).

In terms of Peninsular Spanish wh-question intonation, Prieto (2004) studied the effect of sentence type on the scaling of sentence-initial peaks, focusing on whether higher peaks could be attested for five different sentence types. Two native speaker informants read a series of sentences designed to elicit target utterance production. ${ }^{6}$ The participants were a male speaker from Lleida, Spain and a female speaker from Huesca, Spain. Sentence type was shown to have an effect on the scaling of the first peak, and imperatives and interrogatives had higher peaks than declaratives. As for wh-questions, Prieto found that the most frequent contour contained a final rise, similar in configuration to the final rising or 'polite' pattern mentioned in Quilis (1993). However, one speaker occasionally produced a pattern in which the utteranceinitial rise resulted in a plateau that extended over the utterance until the final stressed syllable, where an F0 fall was exhibited. The production of this contour type was attributed to "dialectal differences" (p. 32). ${ }^{7}$ Falling patterns were also discussed by Dorta (2000), who examined wh-question intonation in Canary Island Spanish.

Sosa (1999), upon examination of wh-question productions of native informants from a mix of regional varieties, proposed the phonological label $\mathrm{H}^{*}+\mathrm{H}$ to account for the higher tonal level of the peak of the rise on the question word in the wh-question contour (p. 148). In a later study, Sosa

5 This excludes, of course, the additional rise on the question word in the whquestion utterance.

6 The notion of task-based effects in intonation research was not the focus of Prieto's study.

${ }^{7}$ It was not clear whether the falling contour productions were included in Prieto's analysis of F0 scaling. 
(2003) analyzed data elicited in both read and spontaneous speech from speakers of four Latin American varieties of Spanish. A total of six participants performed two tasks, the first of which involved the reading aloud of a list of 16 wh-question sentences. For the second task, participants were engaged in spontaneous conversation. Sosa focused his analysis on utterancefinal boundary movements, supported by the claim that the most distinguishing feature between different wh-question contours is whether they end in a rising or falling contour. Results indicated that task-based differences were responsible for variation in contour type production for the Mexican and Colombian participants only, since these speakers preferred the rising contour in the reading task and the falling contour in the spontaneous conversation. The Puerto Rican and Venezuelan speakers produced falling contours consistently in both tasks. ${ }^{8}$ Sosa noted that the data sample was too limited to observe reliable differences in terms of task variability, thus leaving the status of task variation effects in intonation research open to future exploration.

Willis $(2006 / 7,2008)$ studied wh-question tonal levels in two Latin American dialects. Willis (2006/7) examined tonal patterns of declarative, yes/no, and wh-question sentences in Dominican Spanish. Target utterances were elicited in response to contextualized prompts. Willis reported that whquestion initial tonal values were significantly higher than those of the other sentence types examined, suggestive of an initial boundary specification $\% \mathrm{H}^{9}$ The remaining tonal movements included a gradual descent to the nuclear stressed syllable, a nuclear valley, and a boundary rise. Willis (2008) compared Puebla Mexico Spanish wh-question tonal levels and movements with data reported in a previous study on Puebla Mexico Spanish declarative and yes/no question productions (Willis, 2005). The comparison revealed that the wh-question contour started at a significantly higher tonal level than the other sentence types.

In sum, wh-question intonation in Spanish is a relatively understudied linguistic phenomenon. Although Navarro Tomás (1944), Quilis (1993), Sosa (2003), and Hualde (2005) contend that the default configuration is comprised of a descending contour, acoustic analysis of multiple native speaker productions elicited within an experimental framework is limited. Prieto (2004), which is perhaps the only laboratory study to analyze multiple Peninsular Spanish speaker productions, offers no evidence for the global falling contour, but attests the use of a final rise contour and a second contour marked by a nuclear fall. The current study seeks to resolve these contradictory reports by examining the intonation of multiple wh-question utterances produced by six speakers from León, Spain.

\footnotetext{
${ }^{8}$ Although Sosa (2003) refers to 'falling contour' productions repeatedly throughout his paper, the precise acoustic nature of the falling patterns (i.e., gradual falling or nuclear falling (see Section 4.1 of the current paper)) was not investigated.

${ }^{9}$ For a similar discussion of the $\% \mathrm{H}$ boundary tone in Maltese wh-question intonation, see Vella (2007).
} 


\subsection{Laboratory speech versus spontaneous speech in intonation research}

Experimental studies examining intonational differences between read and casual/spontaneous speech have not always found exact correspondence in tonal pattern production across task conditions. For example, Hirschberg (2000) studied American English declarative and interrogative productions and found that frequency of use of the nuclear falling tone was greater in read speech than in spontaneous speech for both sentence types. Work by Warren \& Britian (2000) on the New Zealand English High Rise Terminal also uncovered stylistic variation across data elicitation conditions, reporting that speech data extracted from oral narratives contained a higher overall use of the High Rise Terminal than data extracted from opinion texts. In a more extreme case of task-based variation, Cruttenden (2007) noted that speech samples of one female Glaswegian English speaker elicited in conversational and reading modes demonstrated a case of "intonational diglossia" (p. 257). Specifically, the Glaswegian informant categorically produced a falling default tune, indicative of Urban North British intonation, in a free conversation task, but a rising(-falling) default tune, indicative of Received Pronunciation intonation, in a story reading task. Cruttenden's claim was that different intonational systems underlied tonal production in each task. Whereas previous research had documented variable use of a set of patterns across speech styles, Cruttenden argued that the categorical use of each pattern in different speech styles provided evidence for two distinct intonational systems, or "intonational diglossia."

A number of recent studies have responded to the need for semi-controlled task-based dialogue methodologies as a means of eliciting speaker data, framing their research designs within that of the HCRC Map Task (Anderson et al., 1991). The original HCRC Map Task requires verbal cooperation between two participants: an Information Giver and an Information Follower. The goal of the experimental task is that an Information Giver verbally communicate the route which is printed on his/her map to an Instruction Follower, whose map is without a route, so that the full route can be reconstructed. A number of landmark discrepancies differentiate the two maps, and the speakers must verbally negotiate these differences to successfully complete the task. The names of the specific landmarks are controlled for segmental content so that the phonetic effects of particular phonological phenomena can be observed. ${ }^{10}$ In terms of intonation research, Grice \& Savino (2003) implemented a modified version of the map task methodology to study the tonal patterns of information-seeking and

10 Although Anderson et al. (1991, p. 358-9) explain that speech data elicited in the Map Task experiment may be useful to intonational study, it is not clear how the segmental and prosodic makeup of their target words would facilitate acoustic inspection of the F0 contour or the elicitation of wh-question syntax, for example. 
information-confirmation questions in Bari Italian. They controlled landmark names for prosodic and segmental structure so that comparable analyses across speaker productions and within-speaker repetitions could be carried out. Similarly, Lickley et al. (2005) employed a map task modified for the phonological structure of target landmark names in an experimental study of Dutch falling-rising questions. The phonetic properties of the dialogue speech were compared to those of controlled read aloud utterances. Results indicated similar patterns overall, suggesting that the native speaker informants had successfully set themselves within a spontaneous speech mindset when performing the sentence reading task. The authors concluded that for those interested in acoustic F0 analysis at least, there may be no justification for assuming that spontaneous or task-oriented speech materials are superior to controlled or read speech materials.

Within the Hispanic tradition, research in intonation has traditionally relied on the analysis of multiple repetitions of a set of prepared utterances under some variation of a sentence reading task. While some studies include context-based discourse prompts (e.g., Face, 2002; O'Rourke, 2005; Willis, 2005, 2006/7; Alvord, 2007), others do not (e.g., Prieto, van Santen, \& Hirschberg, 1995; Sosa, 2003; Prieto, 2004; Simonet, 2008 for declaratives). Face (2003) compared declarative tonal patterns known from previous research on laboratory speech with those produced in spontaneous speech. The spontaneous speech data consisted of utterances extracted from interviews of different sorts (e.g., radio call-in shows, television interviews, teacher interviews). A number of differences were found between what had previously been reported for lab speech declaratives and the spontaneous speech declaratives that were examined. Of note in the spontaneous speech corpus were deaccented stressed syllables, early peak alignment, lack of downstepping, and lack of final lowering. More recently, Rao (2009) studied deaccenting in Barcelona, Spain spontaneous speech yes/no questions and Simonet (2008) employed an interactive question-and-answer game methodology to elicit Majorcan Catalan and Majorcan Spanish yes/no questions. In sum, although research on Spanish intonation has grown considerably in recent years, it is clear that the notion of task-based variation has not been addressed in full detail. In this regard, the current study provides a quantitative task-based comparison of speaker productions of the same sentence type across two different tasks. A unique component of the current methodology is that in addition to eliciting speech data with prepared read aloud speech materials, it elicited data from a task-based information gap dialogue activity designed to obtain wh-questions. Although the current methodology does not employ a map per se, it follows in the same methodological trend, since it allows for spontaneous and unscripted interaction in a goal-oriented or task-based dialogue. 


\section{Procedure}

The current study was guided by two main research goals. First, it sought to elicit neutral wh-question intonation in two data elicitation conditions so that a broader range of wh-question tonal patterns could be examined. Second, it sought to determine if task-based differences govern the production of one or another contour type for a given set of León, Spain native speakers.

\subsection{Participants}

Six participants were recruited through social networks and agreed to be recorded for the current research project. Three informants were female (1F, $2 \mathrm{~F}, 3 \mathrm{~F})$, and three were male $(4 \mathrm{M}, 5 \mathrm{M}, 6 \mathrm{M})$. All were native speakers of Peninsular Spanish from the León, Spain area, their age range was between 18 and 33 years, and their average age was 23 years. Responses to a language background questionnaire indicated that although some speakers had spent time abroad during their undergraduate education, the language that they used on a daily basis and in which they felt most comfortable was Spanish. Most informants referred to this language as castellano, or Castilian Spanish, in the questionnaire. No speaker reported having learned a regional language (i.e., Galician, Basque, Catalan) during upbringing.

\subsection{Data elicitation instruments}

All native speaker informants participated in three experiments in the following order: a task-oriented dialogue, referred to here as a 'person identification task'; a computerized sentence reading task; and a language background questionnaire. The participants were recruited through social networks in León, Spain and completed the tasks in the native dialect area. The tasks were carried out in a quiet classroom setting on the local university campus, and the average total time required to complete the tasks was between 30 and 40 minutes.

\subsubsection{Contextualized sentence reading task ${ }^{11}$}

In the contextualized sentence reading task, participants read aloud a series of prepared sentences that were preceded by a discourse context designed to elicit a particular target production: declarative; yes/no question; or whquestion. All utterances were presented in a neutral context, and only wh-

11 Although the sentence reading task was administered second, it is described first here, since it represents the more familiar means of data elicitation in intonation research. 
question productions were analyzed for the current study. ${ }^{12}$ As illustrated in (1), a given set of lexical items was used to form each pragmatic intent. In total, eight lexical combinations were used to create the target utterances. The full set of lexical combinations is provided in Appendix A. ${ }^{13}$

(1) Sample lexical combination: Miraba a mi nene (S/he was watching my boy). Contexto: Papini no estuvo en casa anoche y quiere saber qué pasó. Te pregunta: “Quién miraba a mi nene?”

Context: Papini was not a home last night and wants to know what happened.

He asks you: "Who was watching my boy?"

There were a total of 136 utterances read by each informant. Besides the sentences elicited in a neutral pragmatic context $(n=96), 40$ distracter sentences were included. As can be seen by the sample item in (1), all target sentences were preceded by a contextualized prompt so that the pragmatic intent of the target utterance would be clear. The wh-question corpus consisted of 32 target sentences $(8$ lexical combinations $\times 4$ repetitions $=32$ target productions) per speaker. The discourse contexts and target sentences were presented in PowerPoint. Each slide presented a different context and target sentence. The first click per slide allowed participants to read the context, and the second click allowed participants to see the target sentence. Informants were instructed to read aloud the target utterance only. The first six slides served as a practice session so that participants could become familiar with the pragmatic contexts and the nature of the task. The researcher remained present during the practice session only. Participants took a break after each set of 30 slides, and the computerized instructions indicated that they take a few sips of water during each break. The data were recorded using a SONY HI-MD MZ-RH1 minidisc recorder and Shure WH20 head-mounted microphone, which was placed at a distance of $1 \frac{1}{2}$ to 2 centimeters from each informant's lips. This task lasted approximately 16-20 minutes.

\subsubsection{Person identification task}

The second task was implemented as a means of eliciting wh-question utterances under a somewhat less constrained guise than that of the contextualized reading task. This task was titled a 'person identification task,'

12 The issue of 'focus' (i.e., broad or contrastive) is not easily handled in the study of wh-question intonation (see Ladd, 1996, p. 170-1 for discussion). For this reason, the term 'neutral' was used to describe the pragmatic context provided for the target utterances. It would seem that the neutral contexts used in the current study were similar to the 'broad focus' contextualized prompts provided in Willis $(2006 / 7,2008)$.

13 Target wh-words were limited to quién in the current study to eliminate phonological and/or structural influence of different wh-words on the F0 contour. As an anonymous reviewer points out, work in syntax has revealed differences within the class of wh-words (cf. Cardinaletti \& Starke, 1999; Poletto, 2000). 
since the goal was to identify which of five fictional people was associated with certain quoted phrases. This was an information-gap style task, similar in nature to the HCRC Map Task, and was conducted in pairs. ${ }^{14}$ For the current study, all participants were paired with the researcher. Participants were given five sheets of paper, each of which contained a table divided by a horizontal line (see Appendix B for two sample sheets). The upper panel of the table consisted of a series of dialogue balloons, each of which contained a declarative sentence (e.g., Yo mimaba a la nena. (I was spoiling the girl.)). The full set of declarative sentences that were embedded in the dialogue balloons is provided in Appendix A. In the lower panel of the table, participants saw five cartoon characters. Each character was linked to a dialogue balloon and a declarative utterance different from the set of utterances provided in the upper panel of the table. The objective of the task was to ask the task partner (i.e., the researcher) to which person each of the dialogue balloons from the upper panel was associated. Each informant was instructed to solicit this information with pronominal interrogative syntax (i.e., ¿Quién mimaba a la nena? (Who was spoiling the girl?)). Crucially, these target productions were prosodically identical and segmentally similar to those of the sentence repetition task. The researcher responded to each inquiry by consulting the dialogue balloons in the lower portion of his table and communicating the answer. The researcher also inquired about the dialogue balloons in the upper panel of his task sheets, but did not use pronominal interrogative syntax, to avoid a priming effect. ${ }^{15}$ The participant and the researcher took turns asking about the speakers of the unassociated dialogue balloons until all 25 questions were asked. A sample interaction, based on the task sheets given in Appendix B, is provided in (2).

(2) Sample person identification task interaction Informant: ¿Quién mimaba a la nena?

Researcher: Elena.

Informant: Who was spoiling the girl?

Researcher: Elena.

The instructions for this task were given verbally, and most participants understood the goal of the task immediately. In the case of one participant, it was obvious that the instructions were not clear after the first attempt, so the

14 The term 'information gap' is borrowed from research on pedagogy in input processing and communicative language teaching. For a review of information gap tasks from a second language perspective, see Lee \& VanPatten (2003, pp. 65-67) or Polio \& Gass (1998).

15 The researcher switched between yes/no question and declarative intonation during the course of the task. His productions were of the type ¿Habia alguien que estuviera mimando a la nena? [Was there someone that was spoiling the girl?] or Estoy buscando a alguien que estuviera mimando a la nena. [I'm looking for someone who was spoiling the girl.]. 
verbal instructions were repeated. Participants appeared comfortable with the demands of the task and generally seemed interested in completing the activity. A number of target utterances had to be discarded due to hesitation pauses. This task lasted approximately 6-8 minutes.

\subsubsection{Background questionnaire}

Finally, all participants filled out a background questionnaire designed to elicit information about native and second language use and background and other demographic information reported above. This task lasted approximately 8-10 minutes.

\section{Results}

\subsection{Wh-question patterns}

This section reports on the four contour types that were produced by the six León, Spain speaker informants that agreed to participate in this study. The goal of the current section is to provide a descriptive account of the tonal contour patterns that were attested in the two corpora. Acoustic characterization and quantification of the particular tonal movements that comprised each contour is left for future study. Each of the four contour patterns will be presented and described individually.

The first contour, referred to here as a 'final rise' contour and depicted in Figure 2, was characterized by an initial rise at the start of the utterance to a peak near the offset of the first stressed syllable. This was followed by a gradual descent throughout the second stressed syllable, and finally a nuclear valley followed by a boundary rise. The alignment of the final rise was variable, and although in some cases it began at the start of the final syllable, in other cases it began earlier, during or at the beginning of the penultimate syllable. The issue of variable final rise alignment will be addressed in Section 4.2.

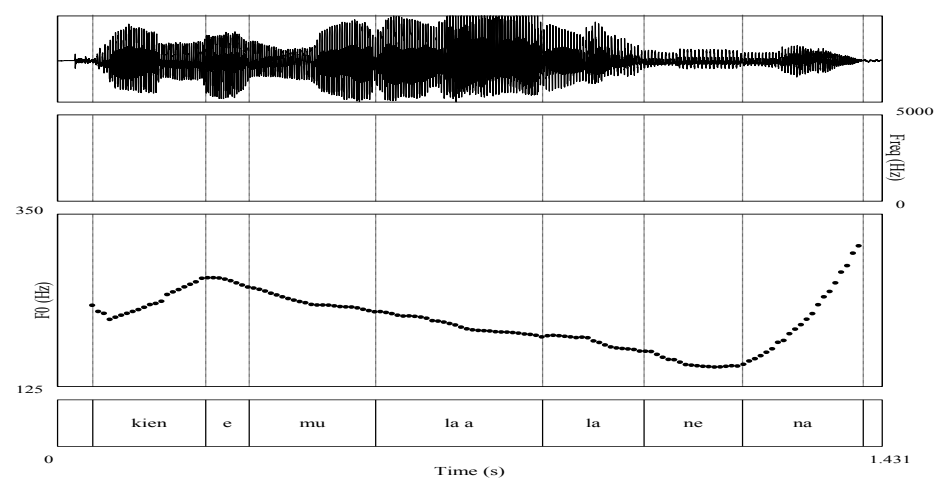

Figure 2. Waveform, spectrogram, and F0 (final rise) contour for ¿Quién emula a la nena? (Who emultates the girl?). F0 contour divided according to syllable structure. 
The second pattern of note is provided in Figure 3 and is referred to here as a 'nuclear circumflex' contour. ${ }^{16}$ It was identified by a rise-fall movement linked to the stressed syllable of the last content word. All other stressed syllables lacked appreciable tonal movement, due to the presence of a tonal plateau that began at the onset of the utterance and lasted until the beginning of the nuclear stressed syllable. In some cases, the initial tonal level was slightly higher, and this was followed by a descent until the nuclear circumflex movement. ${ }^{17}$

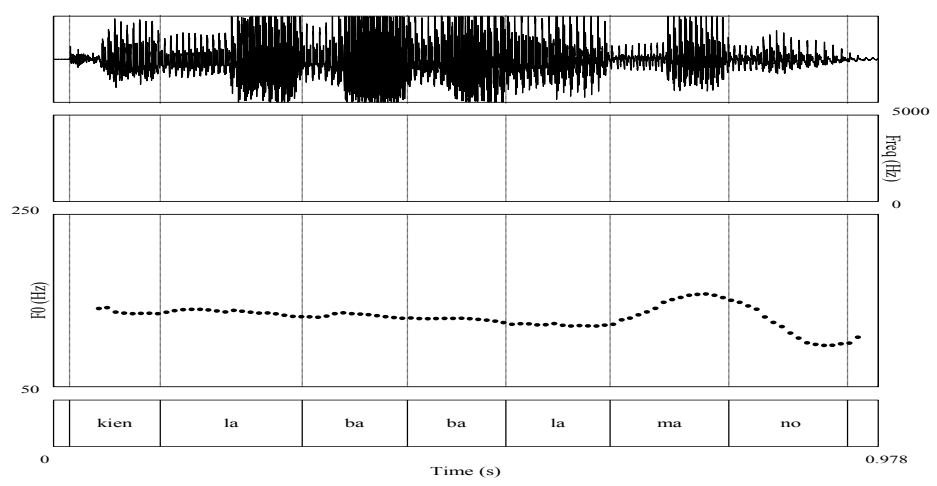

Figure 3. Waveform, spectrogram, and F0 (nuclear circumflex) contour for ¿Quién lavaba la mano? (Who was washing the hand?). F0 contour divided according to syllable structure.

The next contour was a 'global falling' contour without a final rise. An example is provided in Figure 4. In terms of tonal movements, the highest F0 point corresponded to the tonal rise associated to the initial question word. The initial rise was followed by a gradual descent throughout the remainder of the utterance until leveling to a valley at the nuclear stressed syllable, as shown in Figure 4. In some cases the F0 continued its descent throughout the final syllable and did not fall to a valley.

16 Although the term 'circumflex' typically refers to contours with rapid rise-fall movements, it has been used to describe a number of different patterns in Spanish intonation (see Sosa, 1999, p. 219; Martín Butragueño, 2004, p. 358; or Willis, 2005 , p. 335 , for example). In the current study, the term 'nuclear circumflex' was implemented to describe the rapid rise-fall movement that began on the nuclear stressed syllable.

17 This higher tonal level may be attributed to the utterance-initial voiceless velar consonant, known to increase F0 tonal values. Crucially, this higher tonal level could not be attributed to an F0 rise on the pronominal word, as no appreciable rise was evident. 


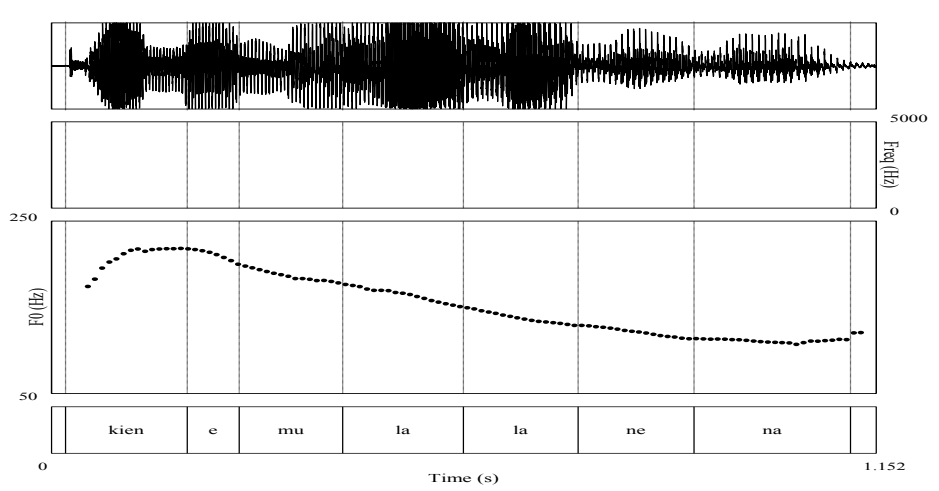

Figure 4. Waveform, spectrogram, and F0 (global falling) contour for ¿Quién emula la nena? (Who emulates the girl?). F0 contour divided according to syllable structure.

The final contour is labeled here a 'nuclear falling' contour, and this pattern contained a series of tonal movements. First, there was a rise to a tonal peak on the question word. This was followed by a plateau that lasted until the nuclear stressed syllable, which contained a falling movement. Finally, a tonal valley ended the utterance. An example is provided in Figure 5.



Figure 5. Waveform, spectrogram, and F0 (nuclear falling) contour for ¿Quién lavaba la mula? (Who was washing the mule?). F0 contour divided according to syllable structure.

\subsection{Task distribution}

We now consider how production of the contour patterns reported in the previous section varied according to the two tasks designed to elicit native speaker production in the current study. We begin by examining the distribution of contour types elicited in the computerized reading task, and 
this information is provided in Table 1 . In addition to providing the total sums and means across the sample of the six speakers, individual results are reported. Given the information provided in Table 1, we see that the final rise contour was the most common contour produced in the reading task. It was produced in $70 \%$ of the total utterances, followed rather evenly by the three other contours: the global falling (13\%); the nuclear circumflex $(10 \%)$; and the nuclear falling (7\%). Closer inspection of individual speaker data reveals that one speaker did not conform to this general trend. Specifically, speaker 6 M's data accounted for nearly all of the global falling productions; he produced the final rise contour in only two of his total 32 utterances. The five other speakers demonstrated a considerably greater preference for the final rise contour in the sentence reading task, using it at rates between $50 \%$ and $100 \%$.

\begin{tabular}{l|cccc}
\hline Speaker & $\begin{array}{c}\text { Final } \\
\text { rise }\end{array}$ & $\begin{array}{c}\text { Nuclear } \\
\text { circumflex }\end{array}$ & $\begin{array}{c}\text { Global } \\
\text { falling }\end{array}$ & $\begin{array}{c}\text { Nuclear } \\
\text { falling }\end{array}$ \\
\hline & $84 \%$ & - & - & $16 \%$ \\
$1 \mathrm{~F}$ & $(27 / 32)$ & & & $(5 / 32)$ \\
\hline & $78 \%$ & $13 \%$ & $3 \%$ & $6 \%$ \\
$2 \mathrm{~F}$ & $(25 / 32)$ & $(4 / 32)$ & $(1 / 32)$ & $(2 / 32)$ \\
\hline & $50 \%$ & $22 \%$ & $19 \%$ & $9 \%$ \\
$3 \mathrm{~F}$ & $(16 / 32)$ & $(7 / 32)$ & $(6 / 32)$ & $(3 / 32)$ \\
\hline & $100 \%$ & - & - & - \\
$4 \mathrm{M}$ & $(32 / 32)$ & & & - \\
\hline & $100 \%$ & - & - & \\
$5 \mathrm{M}$ & $(32 / 32)$ & & & $13 \%$ \\
\hline & $6 \%$ & $28 \%$ & $53 \%$ & $(4 / 32)$ \\
\hline & $(2 / 32)$ & $(9 / 32)$ & $(17 / 32)$ & $7 \%$ \\
Totals & $70 \%$ & $10 \%$ & $13 \%$ & $(14 / 192)$ \\
\hline
\end{tabular}

Table 1. Reading task contour patterns

The second production task designed to elicit wh-question intonation for the current study was the person identification task. We recall that the person identification task was designed to elicit neutral wh-question production by means of an information gap task-based dialogue. The distribution of contour patterns extracted for this task is provided in Table 2. As can be seen, production data was considerably less variable in terms of contour type produced, as compared to the reading task. Whereas four different contours were produced overall in the reading task, only two contours prevailed in the person identification task. These were the final rise contour (57\%) and the nuclear circumflex contour $(43 \%)$. The use of the final rise contour was less in comparison to the reading task ( $57 \%$ to $70 \%$, respectively), and the use of the 
nuclear circumflex contour was considerably greater than in the reading task ( $43 \%$ to $10 \%$, respectively). In terms of individual speaker patterns, we observe that neither contour truly dominated in the person identification task task. Whereas speakers $1 \mathrm{~F}, 2 \mathrm{~F}$, and $4 \mathrm{M}$ favored the final rise pattern, speakers $3 \mathrm{~F}, 5 \mathrm{M}$, and $6 \mathrm{M}$ favored the nuclear circumflex pattern. The range of results was quite variable, with at least one speaker producing either of the two contours categorically or almost categorically. That is, speakers $1 \mathrm{~F}$ and $4 \mathrm{M}$ produced the final rise pattern in $96 \%$ of their utterances, and speaker $6 \mathrm{M}$ produced the nuclear circumflex pattern in $100 \%$ of his utterances. The other speakers produced each of the two contours in approximately half of their total utterances.

\begin{tabular}{l|cccc}
\hline Speaker & $\begin{array}{c}\text { Final } \\
\text { rise }\end{array}$ & $\begin{array}{c}\text { Nuclear } \\
\text { circumflex }\end{array}$ & $\begin{array}{c}\text { Global } \\
\text { falling }\end{array}$ & $\begin{array}{c}\text { Nuclear } \\
\text { falling }\end{array}$ \\
\hline $1 \mathrm{~F}$ & $\begin{array}{c}96 \% \\
(23 / 24)\end{array}$ & $\begin{array}{c}4 \% \\
(1 / 24)\end{array}$ & - & - \\
\hline $2 \mathrm{~F}$ & $52 \%$ & $48 \%$ & - & - \\
& $(13 / 25)$ & $(12 / 25)$ & & - \\
\hline $3 \mathrm{~F}$ & $45 \%$ & $55 \%$ & - & - \\
& $(9 / 20)$ & $(11 / 20)$ & & - \\
\hline $4 \mathrm{M}$ & $96 \%$ & $4 \%$ & - & - \\
& $(23 / 24)$ & $(1 / 24)$ & & - \\
\hline $5 \mathrm{M}$ & $48 \%$ & $52 \%$ & - & - \\
\hline $6 \mathrm{M}$ & $(12 / 25)$ & $(13 / 25)$ & & - \\
& - & $100 \%$ & - & - \\
\hline Totals & $57 \%$ & $43 \%$ & - & \\
& $(80 / 141)$ & $(61 / 141)$ & & - \\
\hline
\end{tabular}

Table 2. Person identification task contour patterns

Table 3 provides a task-based comparison of production data for the current study. There, data for the two most common contour types (i.e., the final rise and the nuclear circumflex) are presented on a speaker-by-speaker basis for each of the two tasks performed. ${ }^{18}$ Data for these two contours only are provided, since together they comprised $89 \%$ (295/333) of the total set of informant productions. One general observation is that two speaker response types can be identified. First, speakers $1 \mathrm{~F}$ and $4 \mathrm{M}$ preferred the final rise contour in both tasks, and use of the nuclear circumflex contour was almost non-existent for them. The trend that emerges for these speakers, then, is a consistent use of the final rise contour in both tasks. A different pattern emerges when data for speakers $2 \mathrm{~F}, 3 \mathrm{~F}, 5 \mathrm{M}$, and $6 \mathrm{M}$ are examined. Whereas

18 Although percentage data only are provided in Table 3, we recall that the actual token counts were given in Tables 1 and 2. 
these speakers used the nuclear circumflex contour at rates between $0 \%$ and $28 \%$ in the reading task, they used the same contour at rates between $48 \%$ and $100 \%$ in the person identification task. In the case of speaker $5 \mathrm{M}$, for example, who failed to use the nuclear circumflex contour in the reading task, we see that its use increased to $52 \%$ in the person identification task. More notably, speaker $6 \mathrm{M}$ increased from $28 \%$ to $100 \%$ use of the nuclear circumflex pattern in the person identification task. Speakers $2 \mathrm{~F}$ and $3 \mathrm{~F}$ increased in nuclear circumflex production as well, from $13 \%$ to $48 \%$ and $22 \%$ to $55 \%$, respectively. The trend that emerges for these four speakers, then, is an increased use of the nuclear circumflex pattern in the person identification task.

\begin{tabular}{l|cc|cc|cc|cc|cc|cc}
\hline Speaker & \multicolumn{2}{c|}{$1 \mathrm{~F}$} & \multicolumn{2}{c}{$2 \mathrm{~F}$} & \multicolumn{2}{c}{$3 \mathrm{~F}$} & \multicolumn{2}{c}{$4 \mathrm{M}$} & \multicolumn{2}{c}{$5 \mathrm{M}$} & \multicolumn{2}{c}{$6 \mathrm{M}$} \\
\hline Task & $\begin{array}{c}\text { RT } \\
\%\end{array}$ & $\begin{array}{c}\text { PIT } \\
\%\end{array}$ & $\begin{array}{c}\text { RT } \\
\%\end{array}$ & $\begin{array}{c}\text { PIT } \\
\%\end{array}$ & $\begin{array}{c}\text { RT } \\
\%\end{array}$ & $\begin{array}{c}\text { PIT } \\
\%\end{array}$ & $\begin{array}{c}\text { RT } \\
\%\end{array}$ & $\begin{array}{c}\text { PIT } \\
\%\end{array}$ & $\begin{array}{c}\text { RT } \\
\%\end{array}$ & $\begin{array}{c}\text { PIT } \\
\%\end{array}$ & $\begin{array}{c}\text { RT } \\
\%\end{array}$ & $\begin{array}{c}\text { PIT } \\
\%\end{array}$ \\
\hline $\begin{array}{l}\text { Final } \\
\text { Rise }\end{array}$ & 84 & 96 & 78 & 52 & 50 & 45 & 100 & 96 & 100 & 48 & 6 & 0 \\
\hline $\begin{array}{l}\text { Nuclear } \\
\text { crmflx. }\end{array}$ & 0 & 4 & 13 & 48 & 22 & 55 & 0 & 4 & 0 & 52 & 28 & 100 \\
\hline
\end{tabular}

Note. RT $=$ Reading task; PIT $=$ Person identification task.

Table 3. Contour type production according to task

The data presented in Table 3 may lead to an alternative interpretation of the person identification task productions for speakers $2 \mathrm{~F}, 3 \mathrm{~F}$, and $5 \mathrm{M}$. That is, although speakers $2 \mathrm{~F}, 3 \mathrm{~F}$, and $5 \mathrm{M}$ demonstrated greater use of the nuclear circumflex pattern in the person identification task, they produced this pattern in approximately half of the target utterances (i.e., $48 \%-55 \%$ ). They employed the final rise contour in the other half of their utterances, suggesting that although the use of the nuclear circumflex pattern increased in the person identification task, neither of the two patterns truly dominated in their sample of unscripted speech. Acoustic inspection of person identification task final rises for speakers $2 \mathrm{~F}, 3 \mathrm{~F}$, and $5 \mathrm{M}$, however, reveals important differences between the rise types produced in this task and those produced in the reading task. Two samples of final rise contours produced by speaker $5 \mathrm{M}$ are given in Figures 6 and 7, corresponding to data elicited in the reading task and the person identification task respectively. Comparison of these productions reveals that although both contours are comprised of a final rise, their alignments are different. Whereas the boundary rise produced in the reading task is aligned to the utterance-final syllable, an expected outcome for neutral interrogatives (cf. Face (2004)), the rise produced in the person identification task is aligned at an earlier point, that is, at the start of the penultimate syllable. The latter rise may not be indicative of a neutral or 'out-of-the-blue' question, but in fact may be reflective of a continuation rise (cf. Frota, 
D'Imperio, Elordieta, Prieto \& Vigário, 2007) produced when speakers resort to listing utterances instead of producing them under standard spontaneous speech conditions. ${ }^{19}$ As indicated in Frota et al., this tonal gesture is marked by a preboundary rise from/on the last stressed syllable into the final boundary syllable (p. 134), as exemplified by Figure $7{ }^{20}$

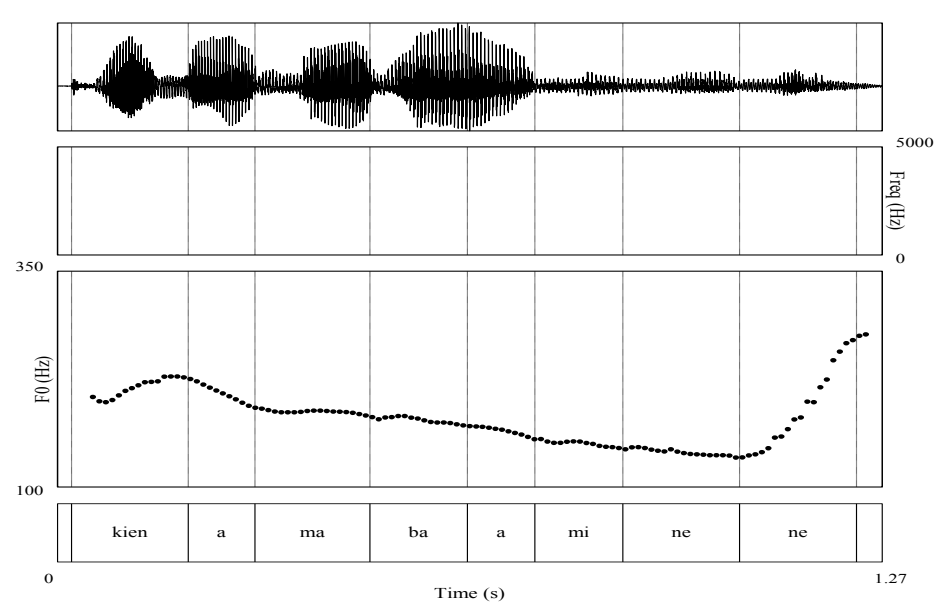

Figure 6. Waveform, spectrogram, and F0 (final rise, ultimate syllable) contour for ¿Quién amaba a mi nene? (Who was loving my boy?). F0 contour divided according to syllable structure.

19 For a full discussion of the phonetics and phonology of this tonal gesture, the reader is directed to the Frota et al. (2007). For the purposes of the current paper, a continuation rise was identified by a boundary rise initiated at any point in the F0 contour prior to the onset of the final stressed syllable. It is worthwhile to point out that the wh-word in Figure 7 lacks the expected rise for a Peninsular Spanish question. This deaccenting may be another consequence of the listing intonation pattern. Impressionistically, the combination of this deaccenting and the early final rise lead to a 'continuation' or 'listing' interpretation (and not to a neutral whquestion interpretation, as produced by the pattern depicted in Figure 6).

20 Listing effect rises of this nature were attested in Simonet (2008), although Simonet did not provide an acoustic characterization of this rise type. 




Figure 7. Waveform, spectrogram, and F0 (final rise, penultimate syllable) contour for ¿Quién lamina la mano? (Who laminates the hand?). F0 contour divided according to syllable structure.

In order to understand the nature of the final rises produced by speakers $2 \mathrm{~F}, 3 \mathrm{~F}$, and $5 \mathrm{M}$, follow-up acoustic inspection was carried out to classify the rise alignment type according to task condition. The criterion that was implemented for rise type identification was its relative alignment, determined by the location of the pitch elbow, or the start of the rise itself. The onset of the consonant of the final syllable was selected for determining penultimate syllable alignment (i.e., pitch elbow before consonant onset) or ultimate syllable alignment (i.e., pitch elbow at or after consonant onset). These data are provided in Table 4 .

\begin{tabular}{l|cc|cc}
\hline & \multicolumn{2}{|c|}{ Reading task } & \multicolumn{2}{c}{ Person identification task } \\
\hline \multirow{2}{*}{ Speaker } & Penult. & Ultimate & Penult. & Ultimate \\
\hline \multirow{2}{*}{$2 \mathrm{~F}$} & $8 \%$ & $92 \%$ & $92 \%$ & $8 \%$ \\
& $(2 / 25)$ & $(23 / 25)$ & $(12 / 13)$ & $(1 / 13)$ \\
\hline \multirow{2}{*}{$3 \mathrm{~F}$} & $13 \%$ & $87 \%$ & $100 \%$ & $0 \%$ \\
& $(2 / 16)$ & $(14 / 16)$ & $(9 / 9)$ & $(0 / 9)$ \\
\hline \multirow{3}{*}{$5 \mathrm{M}$} & $0 \%$ & $100 \%$ & $100 \%$ & $0 \%$ \\
& $(0 / 32)$ & $(32 / 32)$ & $(12 / 12)$ & $(0 / 12)$ \\
Totals & $5 \%$ & $95 \%$ & $97 \%$ & $3 \%$ \\
& $(4 / 73)$ & $(69 / 73)$ & $(33 / 34)$ & $(1 / 34)$ \\
\hline
\end{tabular}

Table 4. Alignment of final rises produced according to task 
Examination of the data in Table 4 reveals that the final rise patterns for speakers $2 \mathrm{~F}, 3 \mathrm{~F}$, and $5 \mathrm{M}$ varied systematically according to the task in which they were produced. A total of $95 \%$ (69/73) of the rises produced in the reading task were aligned to the ultimate syllable, whereas 97\% (33/34) of the rises produced in the person identification task were aligned to the penultimate syllable, suggesting that the person identification rises were produced within continuation or listing sequences. ${ }^{21}$ Reconsideration of the data in Table 3 (i.e., exclusion of $2 \mathrm{~F}$ 's, 3F's, and 5M's personal identification task rises), then, reveals that nearly all of the non-continuation rise contours produced in the person identification task were in fact nuclear circumflex contours.

\section{Discussion}

\subsection{Wh-question intonation}

We begin the discussion section of this paper by acknowledging the presence of multiple wh-question contours in the current sample of native speaker productions and by noting that this is not an unexpected outcome, considering that discourse-level pragmatics have been known to influence whquestion intonation in Spanish. In terms of the default (i.e., unmarked) whquestion pattern, previous researchers had coincided on the notion that some type of a falling contour was the most common pattern (Navarro Tomás, 1950; Quilis, 1993; Hualde, 2005). In the current data sample, however, the global falling contour was produced in 24 of the $192(13 \%)$ total utterances elicited in the reading task, and 17 of these were produced by one speaker. The nuclear falling pattern was produced in 14 of the $192(7 \%)$ total utterances elicited in the same task. No speaker produced either of these patterns in the person identification task. Certainly, the fact that falling contours were attested lends support to the notion that they are available for use in the wh-question inventory. However, neither of the falling contours would seem to be the default pattern for León speakers, given the current findings. ${ }^{22}$ As for the final rise contour (and specifically, the pattern with posttonic rise alignment), it was the most common for five of the six speakers in the reading task. The fact that its use was limited to the reading task suggests that it may not be the default configuration in natural or unscripted speech settings and that it may be motivated by specific stylistic context. We return to this point in the next subsection.

21 This is not an unexpected finding, considering that the task had been designed for speakers to elicit the same type of information in a repeated sequence.

22 Although the form-meaning functions that such falling contours convey were not a focus of the current study, a likely possibility is that speakers chose to convey a pragmatic meaning other than that of a neutral or 'out-of-the-blue' wh-question when reading a number of sentences, leading to the use of a different tonal pattern. 
Turning to a discussion of the nuclear circumflex contour, which was the most common pattern in the person identification task, this is not the first study to report on such a tonal configuration in Spanish intonation. In fact, previous researchers have acknowledged its use in pragmatically marked yes/no questions in Madrid Spanish (Hualde, 2005) and in broad focus declaratives in Mexican Spanish (Kvavic, 1974; Sosa, 1999; Martín Butragueño, 2004; Willis, 2005). Face (2003) also noted that Peninsular Spanish spontaneous speech declaratives are often comprised of a sharp risefall movement on the utterance-final stressed syllable. In the present investigation, four informants employed the nuclear circumflex pattern almost categorically in the person identification task, and not in the sentence reading task, suggesting that León, Spain speakers use this pattern to communicate spontaneous or unscripted neutral wh-questions. Although it may be too early to determine whether the nuclear circumflex contour is the default whquestion pattern in the Peninsular Spanish dialect in general, it is of interest from a systemic standpoint that this contour bears close structural similarities to tonal patterns used to signal other sentence types in other varieties of Spanish.

In terms of the characterization of Peninsular Spanish intonation from a broader perspective, we reconsider claims made in Quilis (1993) and Hualde (2005), who contend that the overall tonal movements of the wh-question contour bear resemblance to those of the declarative, and that this follows from economy in the syntax-prosody interface. The tonal movements that comprise the nuclear circumflex contour, however, do not resemble those of the Peninsular Spanish declarative. Specifically, Peninsular Spanish declaratives are known to display a gradual downstepping pattern throughout their tonal configuration, characterized by a rise on the prenuclear stressed syllable and a reduced rise on the nuclear stressed syllable (cf. Face, 2004). In the nuclear circumflex contour, however, it is the nuclear stressed syllable that receives greatest tonal prominence; the prenuclear stressed syllable in fact lacks appreciable F0 movement. The implication here is that tonal gestures operate in addition to the presence of a question word to communicate sentence type when the nuclear circumflex contour is used. ${ }^{23}$ This would discredit Hualde and Quilis' contention, suggesting that in the case of the León, Spain wh-question, the marking of this sentence type via tonal patterns operates in addition to the use of the pronominal word.

Typologically, the use of the nuclear circumflex pattern lends support to Ladd's (1996) observation that wh-words in languages that exhibit whmovement do not bear accentual prominence. Previous reports of Peninsular Spanish wh-question intonation had indicated that the default tonal pattern consists of an F0 rise on the wh-word, and this seemed to contradict the

${ }^{23}$ Sosa (1999, p. 148) and Willis (2006/7, p. 197) note that an increased utteranceinitial tonal range serves to distinguish wh-questions (in addition to the use of the question word) from other sentence types as well. 
typological prediction given in Ladd (1996). ${ }^{24}$ As for the nuclear circumflex contour attested here, we see a pattern similar to that of the wh-question configuration in English, a language typologically similar to Spanish, since both allow wh-movement. The use of the nuclear circumflex pattern is also in line with Lambrecht \& Michaelis (1998), who claim that wh-words are not typically accented from an intonational standpoint, since their focal status is marked by their form and position within a sentence. Whether or not these typological predictions hold for other dialects of Spanish is left for future investigation.

\subsection{Task variability}

The second general discussion point concerns the effect of data elicitation task on speaker intonation. First, it should be noted that speakers $1 \mathrm{~F}$ and $4 \mathrm{M}$ produced the same contour (i.e., the final rise contour) consistently in both tasks. ${ }^{25}$ Based on these data alone, it would seem appropriate to conclude that the implementation of a task-based dialogue methodology may not be critical for eliciting naturalistic wh-question intonation (cf. Lickley et al., 2005). Consideration of the full sample of data extracted from the current study, and of the data extracted from speakers $2 \mathrm{~F}, 3 \mathrm{~F}, 5 \mathrm{M}$, and $6 \mathrm{M}$ in particular, demonstrates that this is not the case. While the latter group of speakers preferred either the final rise or the global descending contour in the sentence reading task, they decreased the use of these patterns in favor of the nuclear circumflex contour in the person identification task. Speakers 2F, 3F, and 5M, however, employed the circumflex pattern in only half of their utterances in the person identification task, suggesting that final rise patterns persisted. Follow-up acoustic inspection of their final rise productions indicated that person identification task rises were aligned to the penultimate syllable, indicative of a continuation rise pattern (cf. Frota et al., 2007). Once the continuation rise patterns could be eliminated from the total count, it was revealed that nearly all of the remaining person identification task productions were nuclear circumflex contours. Most importantly, four speakers had produced tonal patterns representative of different stylistic contexts when performing each oral data elicitation task, as evidenced by the near categorical production of different contour types in each task. These results confirm that read speech cannot be inferred as phonetically (or phonologically) representative of what occurs in natural interaction, contrary to Lickley et al. (2005). Although read speech may be argued as more sensible from a

${ }^{24}$ It will be recalled that the final rise contour, which predominated in the sentence reading task in the current research paper, also contained an F0 rise on the utterance-initial wh-word.

25 Although quantitative F0 analysis was not carried out to determine if specific phonetic properties differentiate the final rise patterns produced in the two tasks, cursory acoustic inspection did not reveal notable differences. 
methodological and/or analytical standpoint, it is not without linguistic consequence, as the current findings clearly demonstrate.

Knowing that task-based discrepancies exist, it becomes increasingly important to acknowledge that claims about speakers' tonal patterns cannot rely on data elicited in either a sentence reading task or a task-oriented dialogue alone. That is, the fact that the final rise contour predominated in the sentence reading task suggests that this pattern is preferred in formal speech styles (i.e., where speakers resort to 'courteous' speech patterns), and the fact that the nuclear circumflex contour prevailed in the dialogue task suggests that this pattern is preferred in spontaneous or naturalistic speech settings. The implication here is that relying on sentence reading tasks alone should not be assumed to represent naturalistic or unscripted speech patterns for León, Spain speakers. In a similar vein, relying on task-based dialogues alone would not seem to capture the full range of tonal complexity that underlies wh-question intonation. We must conclude, then, that research on Peninsular Spanish whquestion intonation at least, and if not, on other sentences types produced by speakers of this and other dialects of Spanish, would benefit from examining oral data elicited under multiple task type conditions.

Lastly, the current results are reminiscent of what was reported by Cruttenden (2007), who found that one Glaswegian informant adhered to Received Pronunciation intonation in a reading task and to Urban North British intonation in a conversation task. Certainly, the diglossic situation that exists in the United Kingdom may not be wholly comparable to that of the varieties of Spanish spoken in mainland Spain. Nevertheless, the findings on León wh-questions do suggest that different tonal systems exist for different speaking modes and, by inference, that intonational diglossia is prevalent in this dialect area. Furthermore, the fact that task-based effects were not uniform across the current pool of native speaker informants should not come as a surprise, as similar results were reported in Sosa (2003). In Sosa's study, these effects were attributed to dialect differences, although a total of six subjects were sampled from four different dialect areas. In the present study, task-based differences were found across a sample of six speakers, all of whom were from the same dialect area. These findings imply that differences in task performance may not be dialect-specific, as Sosa claims them to be, but speaker-specific. Although the question of why two speakers would respond to the same task in different ways cannot be answered here, what is clear is that for research on Spanish wh-question intonation, the implementation of several task types provides a more comprehensive understanding of wh-question intonation and the multiple contours used to communicate this sentence type. ${ }^{26}$

26 The fact that native Peninsular Spanish speakers have reported anecdotally that verbal reading skills are emphasized in the Spanish education system leads me to believe that speakers of this dialect may be more prone to 'polite' speech in sentence reading tasks. Future work should elaborate on this matter. 


\section{Conclusion}

This paper reported on the results of two production experiments designed to elicit neutral wh-questions by speakers of León, Spain Peninsular Spanish. Speech data were collected in a sentence reading task and an information gap task-based dialogue, referred to here as a 'person identification task.' Four contour patterns were attested across the two oral data elicitation tasks, and the two most prevalent patterns were a final rise contour and a nuclear circumflex contour, the combination of which accounted for $89 \%$ of the total data sample. The fact that the nuclear circumflex contour was evidenced in the current data sample - and not necessarily in previous research on Spanish intonation - was best attributed to the unscripted or naturalistic format of the person identification task. Production of the final rise pattern and the nuclear circumflex pattern varied systematically according to task condition for four of the six speakers, indicating that they had set themselves in two different stylistic contexts when performing each of the tasks. In this regard, a potential case of 'intonational diglossia' was uncovered.

There is little doubt that the current findings can serve to guide future work on Spanish intonation. One issue that must be addressed concerns the pragmatic meanings of the four contours attested here. Although this paper has speculated on the status of the final rise contour and the nuclear circumflex contour, the pragmatic meanings of the two falling contours - both of which are known to exist in other dialects of Spanish - remain to be understood. Another topic for future work concerns a phonological analysis of the tonal patterns comprising the four contour patterns reported here. In particular, the nuclear circumflex pattern is known to communicate sentence types other than the wh-question in other dialects of Spanish, and what remains to be seen is whether the same tonal melody underlies the rapid risefall configuration across these dialects. Finally, it will be of interest to explore the role of task-based variation in intonation research and to examine whether the effects found here are speaker-specific, sentence type-specific, or language-specific.

\section{Acknowledgements}

I am especially thankful to Erik Willis for the guidance that he offered throughout the research process. This project would not have been possible without his help. I am also grateful to Lorenzo García-Amaya, José Ignacio Hualde, and two anonymous reviewers for their help with previous versions of this paper. Evidently, all shortcomings are my own. 


\section{References}

Alvord, S. M. (2007) Spanish intonation in contact: The case of Miami Cuban bilinguals. PhD dissertation, University of Minnesota.

Anderson, N., Bader, M., Bard, E.G., Boyle, E., Doherty, G.M., Garrod, S., Isard, S., Kowtko, J., McCallister, J., Miller, J., Sotillo, C., Thompson, H.S., \& Weinert, R. (1991) The HCRC Map Task Corpus. Language and Speech, 34, 351-366.

Beckman, M. E., \& Pierrehumbert, J. B. (1986) Intonational structure in Japanese and English. Phonology Yearbook, 3, 255-309.

Cardinaletti, A., \& Starke, M. (1999) The typology of structural deficiency: A case study of the three classes of pronouns. In Clitics in the languages of Europe $(\mathrm{H}$. van Riemsdijk, editor), pp. 145-233. Berlin: Mouton de Gruyter.

Cruttenden, A. (2007) Intonational diglossia: a case study of Glasgow. Journal of the International Phonetic Association, 37(2), 257-274.

Dorta, J. (2000) Entonación hispana: Interrogativas no pronominales vs. pronominales. Lingüística Española Actual, 22(1), 51-75.

Face, T. L. (2002) Intonational marking of contrastive focus in Castilian Spanish. Munich: Lincom Europa.

Face, T. L. (2003) Interaction in Spanish declaratives: differences between lab speech and spontaneous speech. Catalan Journal of Linguistics, 2, 115-131.

Face, T. L. (2004) The intonation of absolute interrogatives in Castilian Spanish. Southwest Journal of Linguistics, 23(2), 65-79.

Face, T. L. (2005) F0 peak height and the perception of sentence type in Castilian Spanish. Revista de Lingüística Iberoamericana 2(6), 49-65.

Face, T. L. (2007) The role of intonational cues in the perception of declaratives and absolute interrogatives in Castilian Spanish. Estudios de fonología experimental, 16, 185-225.

Frota, S., D’Imperio, M., Elordieta, G., Prieto, P., \& Vigário, M. (2007) The phonetics and phonology of intonational phrasing in Romance. In Segmental and prosodic issues in Romance phonology (P. Prieto, J. Mascaró \& M.-J. Solé, editors), pp. 131-154. Amsterdam: John Benjamins Publishing Company.

Goldsmith, J. (1979) Autosegmental phonology. New York: Garland.

Grice, M., \& Savino, M. (2003) Map tasks in Italian: Asking questions about given, accessible and new information. Catalan Journal of Linguistics, 2, 153-180.

Hirschberg, J. (2000) A corpus-based approach to the study of speaking style. In Prosody: Theory and Experiment (M. Horne, editor), pp. 335-350. Dordrecht: Kluwer.

Hualde, J.I. (2005) The sounds of Spanish. Cambridge: Cambridge University Press.

Kvavik, K. H. (1974) An analysis of sentence-initial and final intonational data in two Spanish dialects. Journal of Phonetics, 2, 351-361.

Ladd, D. R. (1996) Intonational phonology. Cambridge: Cambridge University Press.

Lambrecht, K. \& Michaelis, L.A. (1998) On Sentence Accent in Information Questions. In Discourse and Cognition: Bridging the Gap (J.P. Koenig, editor), pp. 387-402. Stanford: CSLI Publications.

Lee, J. F. \& VanPatten, B. (2003) Making communicative language teaching happen. New York: McGraw-Hill. 
Lickley, R. J., Schepman, A., \& Ladd, D. R. (2005) Alignment of 'phrase accent' lows in Dutch falling rising questions: Theoretical and methodological implications. Language and Speech, 48(2), 157-183.

Martín Butragueño, P. (2004) Configuraciones circunflejas en la entonación del español mexicano. Revista de Filología Española, 84(2), 347-373.

Navarro Tomás, T. (1944) Manual de entonación española. New York: Hispanic Institute in the United States.

Navarro Tomás, T. (1950) Manual de fonética española. New York: Hispanic Institute in the United States.

O'Rourke, E. (2005) Intonation and language contact: A case study of two varieties of Peruvian Spanish. $\mathrm{PhD}$ dissertation, University of Illinois-Champaign.

Pierrehumbert, J. (1980) The phonology and phonetics of English intonation. $\mathrm{PhD}$ dissertation, MIT.

Poletto, C. (2000). The higher functional field. New York: Oxford University Press.

Polio, C. \& Gass, C.M. (1998) The role of interaction in native speaker comprehension of nonnative speaker speech. The Modern Language Journal, 82(3), 308-319.

Prieto, P. (2004) Phonological targets in the tonal space. In T. L. Face (Ed.), Laboratory Approaches to Spanish Phonology. Berlin: Mouton de Gruyter.

Prieto, P., van Santen, J., \& Hirschberg, J. (1995) Tonal alignment patterns in Spanish. Journal of Phonetics, 24, 445-473.

Quilis, A. (1987) Entonación dialectal hispánica. In Actas del I Congreso Internacional sobre el Español de América (H. López Morales \& M. Vaquero, editors), pp. 117-164. San Juan, Puerto Rico: Academia Puertorriqueña de la Lengua Española.

Quilis, A. (1993) Tratado de fonología y fonética españolas. Madrid: Editorial Gredos.

Rao, R. (2009) Deaccenting in Spontaneous Speech in Barcelona Spanish. Studies in Hispanic and Lusophone Linguistics. 2(1), 31-75.

Simonet, M. (2008) Language contact in Majorca: An experimental sociophonetic approach. University of Illinois at Urbana-Champaign: Doctoral dissertation.

Sosa, J. M. (1999) La entonación del español. Madrid: Cátedra.

Sosa, M. (2003) Wh-questions in Spanish: Meanings and configurational variability. Catalan Journal of Linguistics, 2, 229-247.

Vella, A. (2007) The phonetics and phonology of wh-question intonation in Maltese. In Proceedings of the XVI International Conference of Phonetics Sciences (J. Trouvain \& W. J. Barry, editors), pp. 1285-1288. Saarbruken, Germany.

Warren, P., \& Britian, D. (2000) Prosody and intonation of New Zealand English. In New Zealand English (A. Bell \& B. Kuiper, editors), pp. 99-115. Wellington: Victoria University Press.

Willis, E. (2004) Dominican Spanish absolute interrogatives in broad focus. In Laboratory approaches to Spanish phonology (T. L. Face, editor), pp. 61-79. Berlin: Mouton de Gruyter.

Willis, E. (2005) Tonal levels in Puebla Mexico Spanish declaratives and absolute interrogatives. In Theoretical and experimental approaches to Romance linguistics (R. Gass \& E. Rubin, editors), pp. 351-363. Amsterdam: John Benjamins.

Willis, E. (2006/7) Utterance Signaling and Tonal Levels in Dominican Spanish Declaratives and Interrogatives. Journal of Portuguese Linguistics, 5/6, 147-178. 
Willis, E. (2008) Tonal characteristics of pronominal interrogatives in Puebla Mexico Spanish. In Fonología instrumental: Patrones fónicos y variación (E. Herrera Z. \& P. M. Butragueño, editors), pp. 357-376. México, D.F.: El Colegio de México, A.C.

Willis, E. \& Henriksen, N. (2008). León Spain Spanish intonation: the case of the prenuclear pitch accent. Paper presented at Laboratory Approaches to Spanish Phonology 4. Austin, TX.

\author{
Nicholas C. Henriksen \\ 848 Ballantine Hal \\ 1020 E. Kirkwood Ave \\ Bloomington, IN 47405-7103 \\ nhenriks@indiana.edu
}




\section{Appendix A.}

Target pronominal utterances used in the contextualized reading task:

¿Quién emula a la nena? 'Who emulates the girl?'

¿Quién mimaba a la nena? 'Who was spoiling the girl?'

¿Quién miraba a mi nene? 'Who was watching my boy?'

¿Quién amaba a mi nene? 'Who was loving my boy?'

¿Quién lavaba la mula? 'Who was washing the mule?'

¿Quién alaba la mula? 'Who praises the mule?'

¿Quién adora la mona? 'Who adores the monkey?'

¿Quién mimaba la mona? 'Who was spoiling the monkey?'

Declarative phrases provided in person identification task:

Yo miraba la bola. I was watching the ball.

Yo lavaba la mano. I was washing the hand.

Yo nomino a la nena. I nominate the girl.

Yo lamino la mano. I laminate the hand.

Yo nomino a la mima. I nominate the mime.

Yo mimaba a la nena. I was spoiling the girl.

Yo miraba la vela. I was watching the candle.

Yo alabo la mula. I praise the mule.

Yo emulo la mona. I emulate the mule.

Yo lamino la bola. I laminate the ball.

Yo mimaba la mona. I was spoiling the monkey.

Yo miraba la lila. I was watching the lilac.

Yo lamino la vela. I laminate the candle.

Yo amaba a la nena. I was loving the girl. 
Appendix B. Sample person identification task sheets.

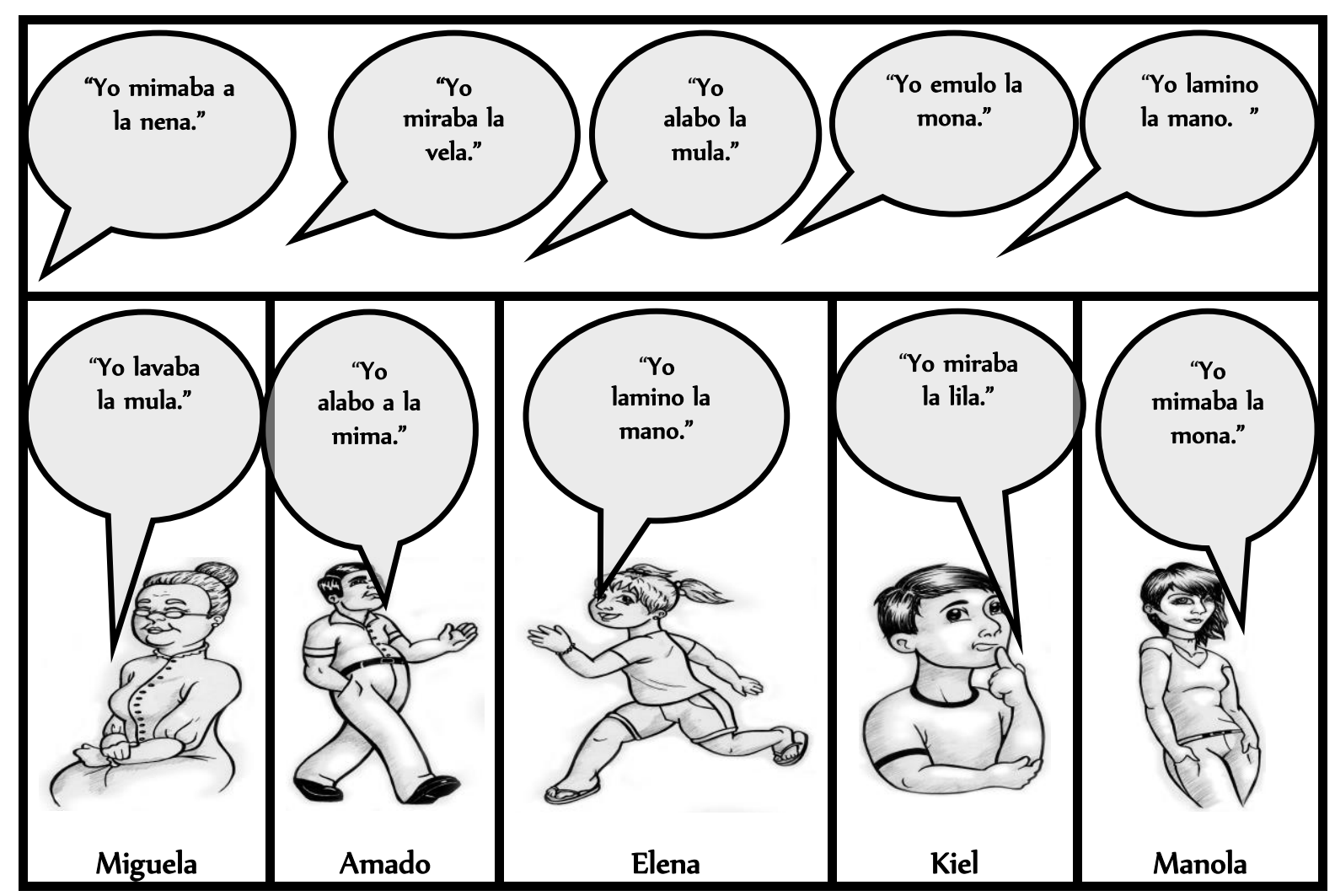




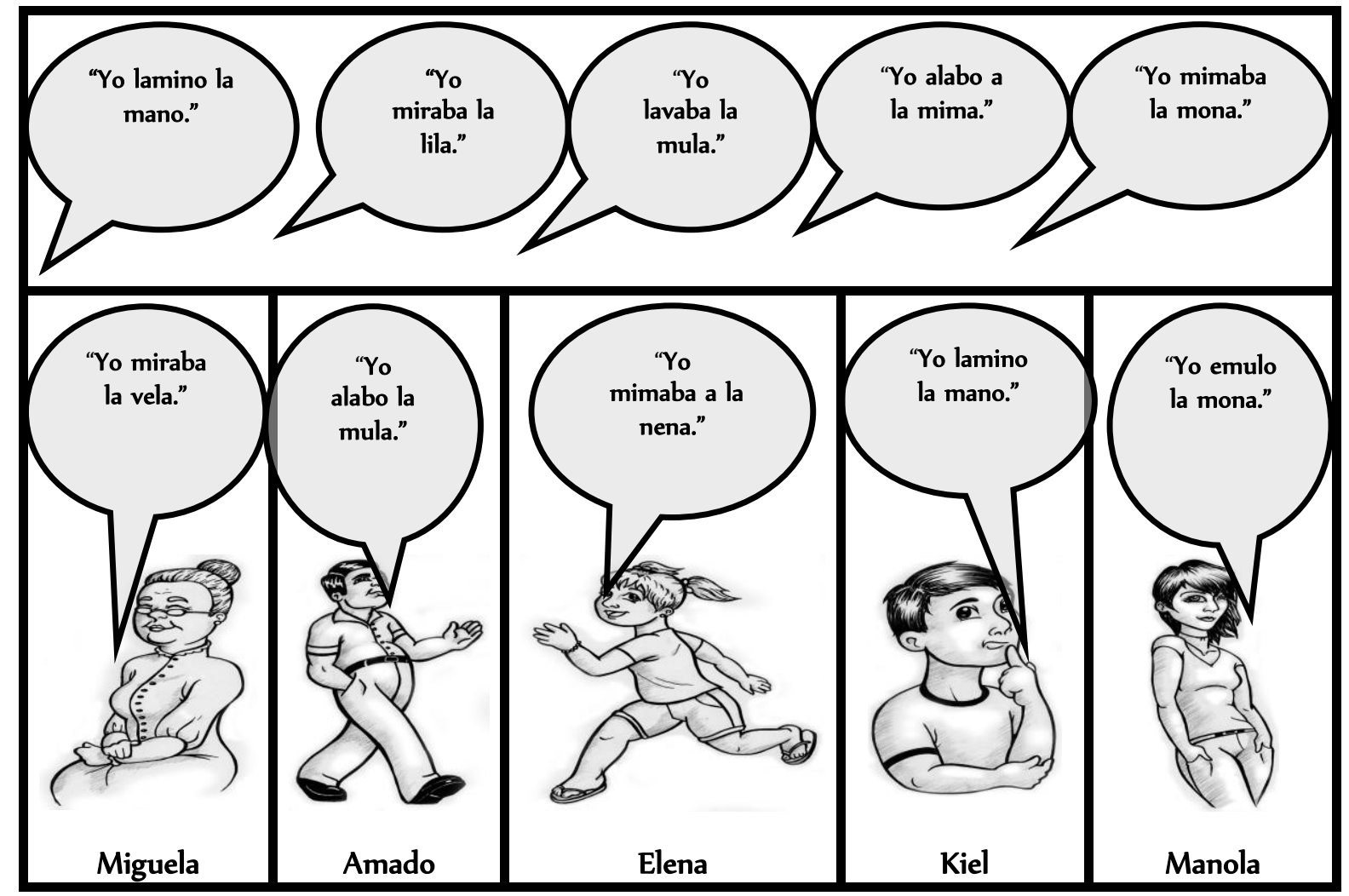

